\title{
Ensino médico e o perfil do profissional de saúde para o século XXI
}

Marcio José de Almeida ${ }^{1}$

\section{Introdução}

A proximidade do final do Século $X X$ faz com que se passe a viver, no dia-adia, o clima de reflexões, expectativas e projeções que caracterizam a semana entre o Natal e o Ano Novo. O título deste artigo e o tema do Painel que o motivou refletem esse clima.

Há uma certa "mística" em torno de abordagens desse tipo e seria difícil escrever algo sobre "o perfil do profissional de saúde para o próximo século" sem cair num certo exercício de futurologia. Nada contra os futurólogos. Mas prefiro um terreno mais palpável e exercitar algumas análises acerca dos "anos iniciais do Século XXI". Afinal, esses anos estão próximos e será durante os mesmos que as diretrizes das políticas para o ensino médico, para a saúde e para a educação serão executadas pelos Governos recentemente eleitos.

Além de algumas idéias apresentadas por ocasião do Painel realizado em Botucatu, entendo ser pertinente incluir no artigo alguns conteúdos que abordei em estudo recentemente concluído (Almeida, 1997) e também outros elementos que constam da "Contribuição para as novas diretrizes curriculares dos cursos de graduação da área de saúde" (REDE UNIDA, 1998), de cuja sistematização participei diretamente.

\footnotetext{
"Tema do "Painel de Debate" promovido, em agosto de 1997, pelas disciplinas de Pedagogia Médica e Didática Especial dos Cursos de Pós-Graduação da Faculdade de Medicina de Botucatu-UNESP. As anotações da exposição feita no painel foram complementadas com análises registradas na tese de doutoramento do autor, defendida em dezembro de 1997, na Faculdade de Saúde Pública da USP.

${ }^{1}$ Vice-reitor da Universidade Estadual de Londrina. E-mail: almeida@inbrapenet.com.br
} 
O título do artigo interliga duas dimensões da problemática da educação médica: o ensino e a prática profissional. São duas das três dimensões centrais do marco teórico-conceitual da educação médica com o qual me identifico e que orienta meu pensamento e minha ação no campo da formação e capacitação de recursos humanos em saúde. A terceira dimensão deste marco é constituída pelas relações internacionais que existem nos processos de produção dos serviços de saúde e de formação de profissionais de saúde.

\section{O marco teórico-conceitual da Educação Médica}

Entendendo o marco teórico-conceitual como a apresentação da educação médica em suas linhas ou características mais significativas, permitindo um certo nível de generalidade que a torna aplicável a distintas situações, é imprescindível considerar dois estudos produzidos no contexto do movimento da educação médica latino-americana: o de Garcia (1972) e o de Andrade (1979).

Para Garcia (1972), a educação médica, entendida como processo de produção de médicos, constitui-se de dois componentes inseparáveis: o processo de ensino e as relações de ensino (Figura 1).

Figura 1 - Esquema do marco teórico da educação médica

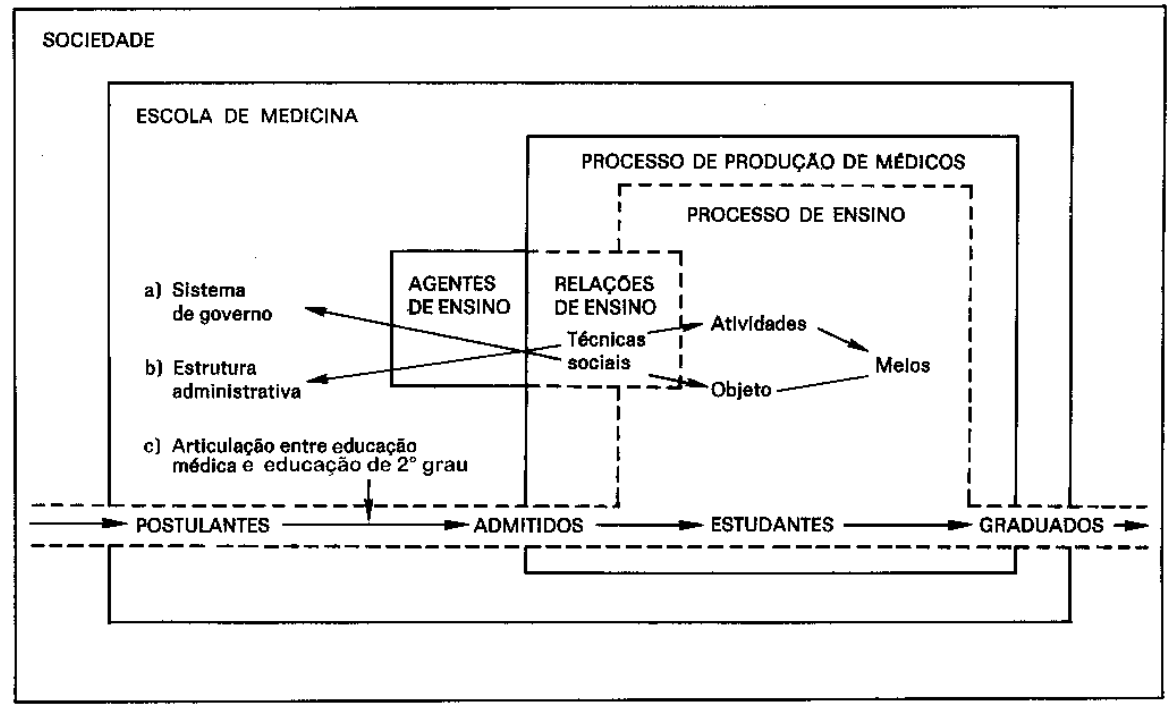

Fonte: Nunes (1989)

O processo de ensino pode ser definido como o conjunto de momentos sucessivos que envolvem atividades, meios, conteúdos e objetivos de ensino pelos quais o estudante passa até transformar-se em médico. As relações de ensino são as conexões ou vínculos que se estabelecem entre as pessoas 
participantes do processo de produção de médicos e são resultantes do papel que esses indivíduos desempenham no ensino médico. Estas relações podem ser de dois tipos: a) as que se estabelecem entre os agentes de ensino e todo o processo de ensino; b) as que se instituem entre os próprios agentes de ensino. O primeiro tipo configura o que se chama relações técnicas e o segundo, relações sociais.

Os agentes de ensino são indivíduos que, ao participar da educação médica, ocupam determinadas posições, variáveis conforme o modo de produção do médico. Atualmente, o professor universitário é o mais característico dos agentes de ensino. O estudante de medicina, embora considerado também um dos agentes, na forma

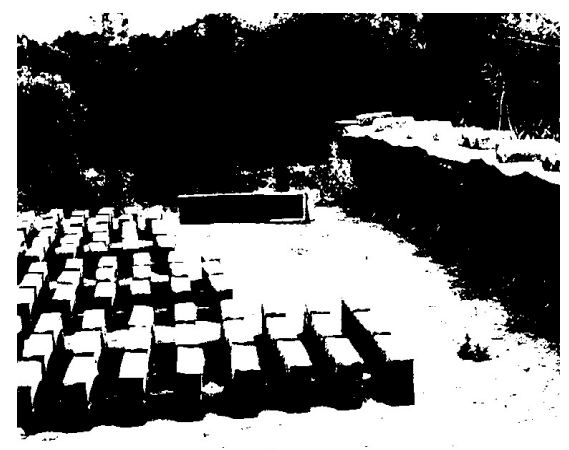
dominante de produção de médicos na América Latina está numa posição dependente que o define mais como objeto do que como sujeito da educação médica.

Segundo García (1972, p.4):

\begin{abstract}
"la categoria de "estudiante" implica una serie de concesiones con respecto a otros grupos de la sociedad como, por ejemplo, el eximirse de realizar un trabajo productivo. Esta disociación entre estudio y trabajo constituye uno de los problemas más importantes de la educación actual, y su superación, junto con cambios en las relaciones de enseñanza, llevará a profundas transformaciones en la formación de médicos".
\end{abstract}

A ordem institucional da educação médica, ou seja, a escola de medicina com suas características internas, tais como sistema de governo, estrutura administrativa, articulação que estabelece com o ensino médio, emerge do processo de produção de médicos, isto é, do processo de ensino e das relações que se produzem no interior do próprio processo.

A forma institucional que um determinado modo de produção de médicos adquire constitui a superestrutura do processo; o processo e as relações de ensino, sua infra-estrutura.

Com base nos resultados do estudo que realizou, García (1972, p.241) registra que "(...) parece confirmar la teoria que dá importancia a la estructura de las relaciones que surgen en el proceso de enseñanza (...) las relaciones en la enseñanza constituyem el fundamental de todo cambio educacional profundo". Uma vez que o modo de formar médicos determina ${ }^{2}$ a ordem institucional, é esperado que mudanças no primeiro levem a transformações substanciais na forma de organização da educação médica.

${ }^{2}$ A palavra determinação, cujo uso já está consagrado nas Ciências Sociais, é portadora de uma desvantagem, pois leva a um raciocínio de que "isto causa aquilo". Na verdade, o conceito de determinação refere-se à existência de inter-relações dialéticas e ao estabelecimento de causalidades com base em análises históricas. 
Esta concepção não implica o desconhecimento da influência que as características da escola (a superestrutura) possam ter, ainda que de forma limitada, sobre o processo de produção de médicos (a infra-estrutura). É possível que mudanças produzidas no processo de ensino possam ser limitadas (no tempo e no espaço) ou anuladas porque a estrutura interna, acadêmico-administrativa, da faculdade e/ou da universidade não permite sua aplicação. Mas o processo de produção de médicos não é um processo isolado, relaciona-se intimamente à estrutura econômica predominante na sociedade, na qual se desenvolve e estabelece relações com outros processos $e$, em especial, com a prática médica.

A prática médica está ligada à transformação histórica do processo de produção econômica. A estrutura econômica determina, como acontece com todos os demais componentes da sociedade, a importância, o lugar e a forma da medicina na estrutura social. Semelhante determinação não corresponde a uma causalidade simples, mas a outra, de tipo estrutural: a determinação em última instância. Esta consiste na abertura de espaços fora do alcance do econômico, ou seja, permite uma autonomia relativa do objeto (no caso, a prática médica) possibilitando a entrada em jogo de novas causas e novos efeitos. Entre esses estão os provenientes das relações de força estabelecidas entre os distintos grupos sociais e o Estado em torno de demandas relativas à problemática da saúde.

O segundo estudo a ser considerado é o de Andrade (1979), para quem o marco conceitual da educação médica encontra-se no centro de uma intrincada rede de relações e resulta da interação entre os diversos elementos que dela participam, dentre os quais se destacam, por sua importância: a estrutura social, econômica e da prática médica em cada país; o currículo; as relações internas do processo de produção de médicos, a ideologia dominante no âmbito profissional e a estrutura de poder internacional (Figura 2).

Figura 2 - Relações externas do marco conceitual da educação médica em países dependentes

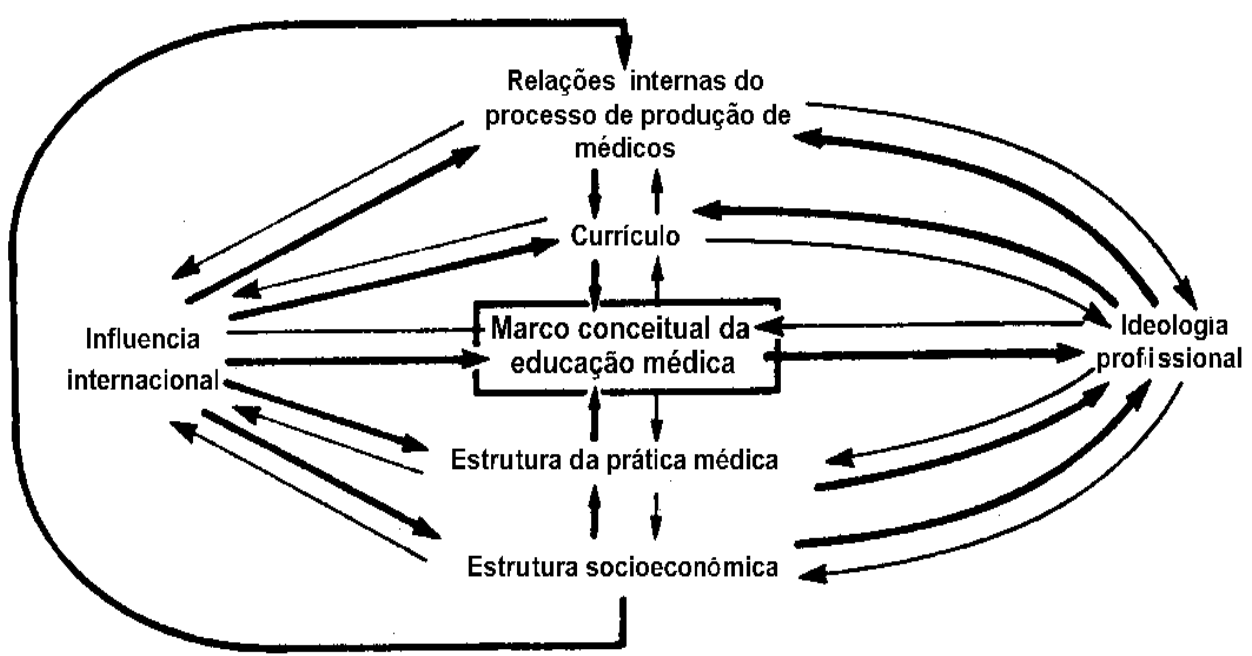

Nota: as lınhas mais grossas assinalam a direção da influência dominante.

Fonte: Andrade (1979) 
Além dos estudos de Garcia e Andrade, destaco os realizados por Arouca (1975), Donnangelo (1975) e Schraiber (1989), que contribuem com análises relevantes para a configuração $e$ atualização do marco teórico da educação médica.

Recentemente, relacionando a situação da Residência Médica no Brasil com o desenvolvimento da educação médica, Feuerwerker (1997) afirmou que "pensar a Residência Médica como parte do processo de formação dos médicos pode ser um passo essencial para interferir, de fato, na definição do perfil dos profissionais médicos". Esse papel, o da formação de especialistas, não era enfatizado, no início da formulação do marco teórico da educação médica, conforme se pode verificar pelo esquema apresentado anteriormente (Figura 1), no qual só está assinalada a articulação entre educação médica e a educação de segundo grau (ensino médio).

$\mathrm{O}$ marco conceitual da educação médica, resumidamente abordado neste artigo, é referencial decisivo para a compreensão dos dilemas e das propostas de mudança na educação médica.

\section{Dilemas e propostas de mudança}

A partir da metade dos anos 80 , com a democratização da vida nacional e o desenho político-jurídico de um novo sistema de saúde, o ensino médico brasileiro começou a sair da letargia que o acometia desde os anos 70 .

Mas é somente com o início da construção político-organizativa do Sistema único de Saúde (SUS), já no início dos anos 90, que as debilidades do ensino médico brasileiro e o questionamento mais incisivo do perfil dos produtos das escolas médicas adquirem uma visibilidade social.

$O$ revigoramento da Associação Brasileira de Educação Médica (ABEM), a articulação da Comissão Interinstitucional Nacional de Avaliação do Ensino Médico (CINAEM), a crítica de setores do novo Sistema de Saúde em construção e o desenvolvimento do processo de avaliação são iniciativas que respondem a uma crescente cobrança da sociedade. Esta manifesta sua insatisfação frente aos médicos formados pelas escolas, despreparados para as novas práticas profissionais, sociais e institucionais que passam crescentemente a ser exigidas pelas iniciativas voltadas à concretização de um novo Modelo Assistencial no âmbito do Sistema único de Saúde (SUS).

Além do Brasil, outros países da América Latina constituem cenário, na década de 80 , de importantes acontecimentos e processos, entre os quais se destacam: a) estudos de avaliação da proposta Integração Docente

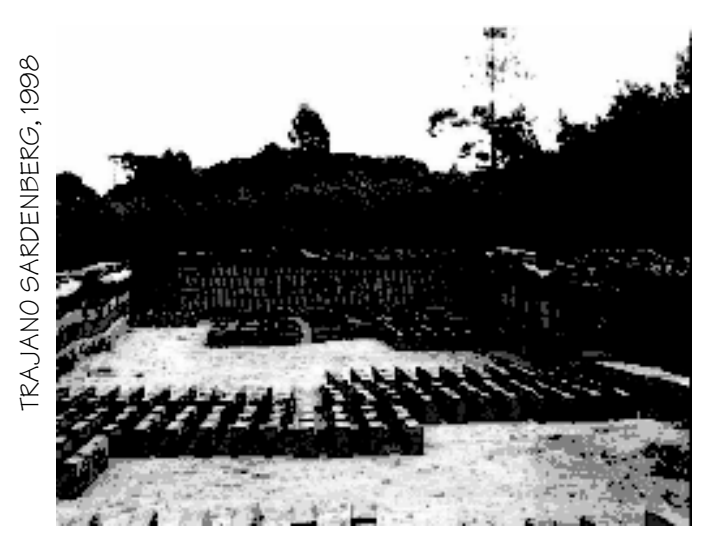
Assistencial, IDA, com ênfase para o realizado pela Federação Panamericana de Faculdades e Escolas de Medicina, FEPAFEM/OPS/Kellogg; b) aplicação de uma nova proposta, desenvolvida pela OPS (Organização Panamericana de Saúde), denominada Análise Prospectiva das Profissões de Saúde; c) convocação, pela União das Universidades da América Latina, UDUAL, de uma Conferência Integrada de Ciências da Saúde e a realização de debates preparatórios 
pela Associação Latino-americana de Faculdades e Escolas de Medicina, ALAFEM, e outras entidades, com apoio da OPS; d) convocação e realização, em 1988, da $1^{a}$ Conferência Mundial de Edimburgo, precedida da realização de estudos que a preparariam, realizados pela FEPAFEM, com apoio da Fundação Kellogg.

Com a realização dos eventos internacionais, verifica-se que os dilemas do ensino médico fazem parte das preocupações dos organismos internacionais, não sendo uma realidade somente brasileira. Esta abrangência fica mais evidente nos anos 90.

Em 1991, a coordenação do Programa para a América Latina e o Caribe, da Fundação Kellogg, comunicou e convidou instituições universitárias da área da saúde detentoras, no mínimo, de cursos de graduação de Medicina e de Enfermagem, a participar de Uma Nova Iniciativa na Educação dos Profissionais de Saúde: União com a Comunidade, referida mais comumente pela sigla UNI.

Em 1992, a OPS difundiu, por intermédio das Associações Nacionais de Educação Médica e da FEPAFEM, um documento de referência com o título "As Mudanças na Profissão Médica e sua Influência sobre a Educação Médica”, especialmente elaborado para as discussões preparatórias da $2^{a}$ Conferência Mundial de Educação Médica.

Esta realizou-se em 1993, em Edimburgo; no mesmo ano, foi realizada a

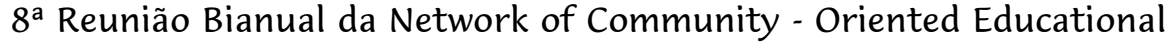
Institutions for Health Sciences, em Sherbrook (Canadá). Em Edimburgo foi apresentada, pela Organização Mundial de Saúde, a proposta "Changing medical education and practice: an agenda for action" e com a Reunião de Sherbrook a proposta da Network passou a ter maior visibilidade no Brasil e nos demais países da América Latina.

Em 1994, durante o Encontro Continental de Educação Médica, promoção conjunta da FEPAFEM e da ALAFEM, realizado em Punta del Este (Uruguai), a OPS apresentou a proposta "Gestão de Qualidade na Educação Médica".

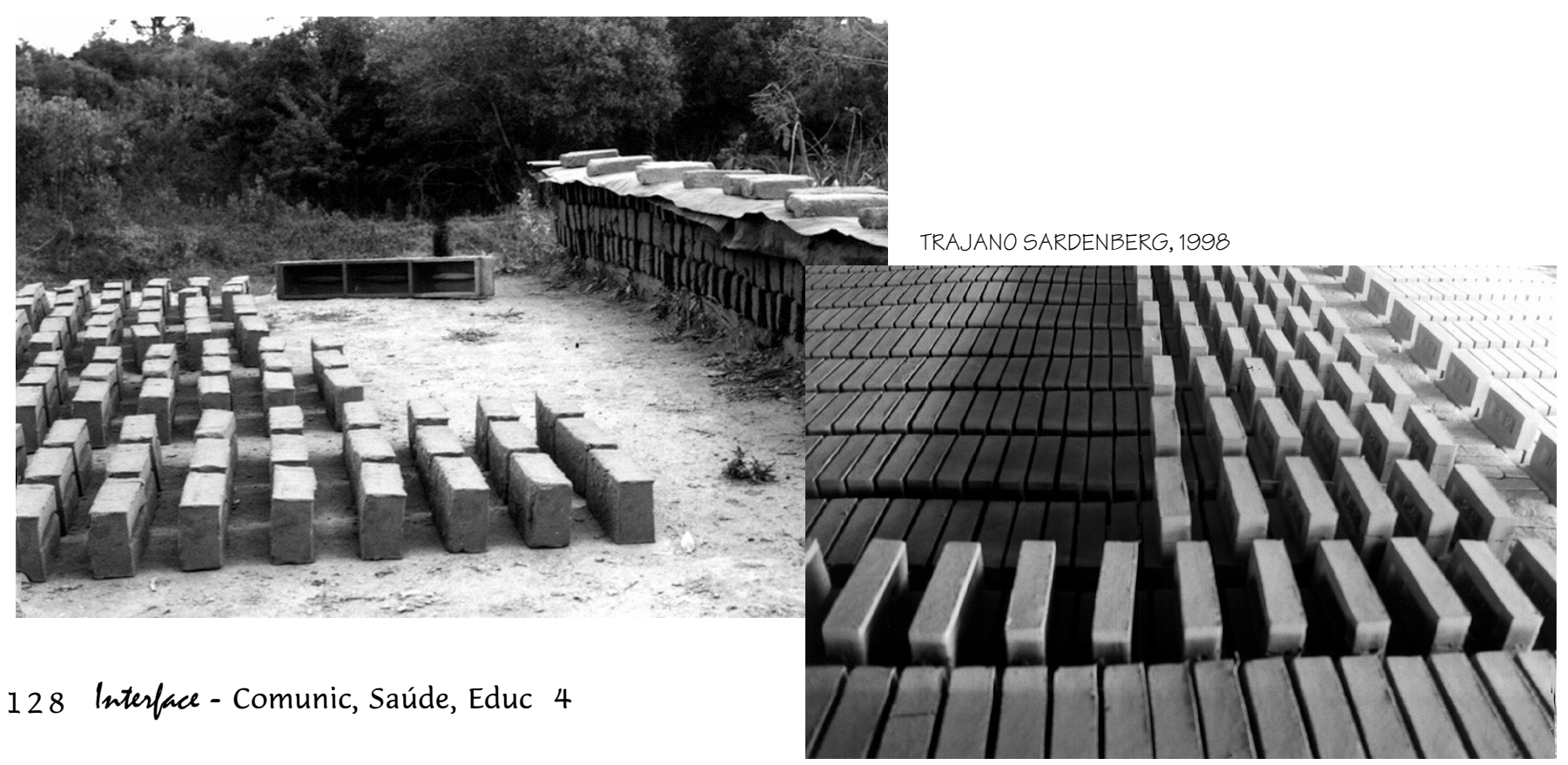


As características fundamentais dessas propostas estão apresentadas abaixo.

Quadro 1 - Características das propostas de mudança na Educação Médica nos anos 80

\begin{tabular}{|c|c|c|c|c|}
\hline & UNI & CHANGING & NETWORK & $\begin{array}{l}\text { GESTÃO DE } \\
\text { QUALIDADE }\end{array}$ \\
\hline Origem & América Latina & $\begin{array}{l}\text { Europa e } \\
\text { América do } \\
\text { Norte }\end{array}$ & $\begin{array}{c}\text { Europa e } \\
\text { América do } \\
\text { Norte }\end{array}$ & América Latina \\
\hline $\begin{array}{l}\text { Área de } \\
\text { atuação }\end{array}$ & América Latina & Mundial & Mundial & América Latina \\
\hline $\begin{array}{r}\text { Antecedentes } \\
\text { imediatos }\end{array}$ & $\begin{array}{c}\text { IDA, EMA, } \\
\text { Edimburgo } \\
1988\end{array}$ & $\begin{array}{c}\text { Edimburgo } \\
1988\end{array}$ & Alma-Ata 1978 & $\begin{array}{c}\text { Havana 1991, } \\
\text { Edimburgo } \\
1988\end{array}$ \\
\hline Promoção & $\begin{array}{l}\text { Fundação } \\
\text { Kellogg }\end{array}$ & OMS & Network & OPS \\
\hline Financiamento & $\begin{array}{l}\text { Fundação } \\
\text { Kellogg }\end{array}$ & $\begin{array}{l}\text { OMS e } \\
\text { Fundação } \\
\text { Kellogg }\end{array}$ & $\begin{array}{l}\text { Governo da } \\
\text { Holanda, } \\
\text { Fundação } \\
\text { Rockefeller, } \\
\text { Fundadção } \\
\text { Kellogg } \\
\text { e OMS }\end{array}$ & OPS \\
\hline $\begin{array}{r}\text { Principais } \\
\text { atores } \\
\text { institucionais }\end{array}$ & $\begin{array}{l}\text { Instituições } \\
\text { universitárias } \\
\text { da área de } \\
\text { saúde, órgãos } \\
\text { públicos de } \\
\text { serviços de } \\
\text { saúde, } \\
\text { organizações } \\
\text { comunitárias e } \\
\text { Fundação } \\
\text { Kellogg }\end{array}$ & $\begin{array}{l}\text { OMS, entidades } \\
\text { médicas, órgãos } \\
\text { públicos e } \\
\text { privados de } \\
\text { serviços de } \\
\text { saúde e } \\
\text { instituições } \\
\text { universitárias da } \\
\text { área de saúde }\end{array}$ & $\begin{array}{c}\text { Instituiçõos } \\
\text { universitárias } \\
\text { da área de } \\
\text { saúde, } \\
\text { organizações } \\
\text { comunitárias e } \\
\text { Network }\end{array}$ & $\begin{array}{l}\text { OPS, ALAFEM e } \\
\text { FEPAFEM }\end{array}$ \\
\hline $\begin{array}{r}\text { Principais } \\
\text { sujeitos sociais }\end{array}$ & $\begin{array}{l}\text { Professores e } \\
\text { estudantes } \\
\text { universitários, } \\
\text { gestores dos } \\
\text { serviços de } \\
\text { saúde e líderes } \\
\text { comunitários }\end{array}$ & $\begin{array}{l}\text { Professores } \\
\text { universitários e } \\
\text { profissionais dos } \\
\text { serviços de } \\
\text { saúde }\end{array}$ & $\begin{array}{c}\text { Professores e } \\
\text { estudantes } \\
\text { universitários, } \\
\text { líderes } \\
\text { comunitários }\end{array}$ & $\begin{array}{c}\text { Professores } \\
\text { universitários e } \\
\text { profissionais } \\
\text { dos serviços de } \\
\text { saúde }\end{array}$ \\
\hline Situação atual & $\begin{array}{l}\text { Implantada, } \\
\text { com processos } \\
\text { em andamento } \\
\text { e resultados } \\
\text { parciais/ } \\
\text { intermediários }\end{array}$ & Em implantação & Em implantação & $\begin{array}{l}\text { Interrompida } \\
\text { na fase de } \\
\text { concepção }\end{array}$ \\
\hline
\end{tabular}

Fonte: Almeida (1997) 
Uma análise acerca da concepção teórico-metodológica, do desenvolvimento e dos resultados dessas propostas foram objeto de estudo específico (Almeida, 1997). Em síntese, o estudo permitiu caracterizar a iniciativa UNI como a mais consistente e estruturada. Apesar de conter algumas debilidades, combinando em graus variáveis elementos das outras propostas, ela tem sido a responsável pelos processos de mudança mais avançados.

\section{A construção de um novo perfil profissional}

Hoje, e com maior ênfase nos próximos anos, portanto já no Século XXI, a diversidade e a complexidade dos campos de atuação dos profissionais de saúde que decorrem do contínuo desenvolvimento científico-tecnológico e dos novos quadros demográfico-sanitários exigem novos delineamentos para o âmbito específico de cada profissão. Ainda assim, os profissionais de saúde deverão, nos próximos anos, estar dotados de competências (conhecimentos, habilidades e atitudes) que possibilitem a sua interação $e$ atuação multiprofissional, promovendo e executando ações integrais de saúde que beneficiem indivíduos e comunidades.

Recentemente, no contexto das discussões provocadas pelo Edital 04/97, da Secretaria de Educação Superior do Ministério da Educação (SESU/MEC), os projetos UNI de Salvador, Botucatu, Marília, Brasília, Natal e Londrina, refletindo sobre suas práticas e processos de mudança, apresentaram sua contribuição para as novas diretrizes curriculares dos cursos da área de saúde (REDE UNIDA, 1998), documento que apresenta um novo perfil para o médico a ser formado:

\footnotetext{
- estar estimulado e capacitado para a prática da educação permanente, especialmente para a auto-aprendizagem; - exercer a medicina utilizando procedimentos diagnósticos e terapêuticos validados cientificamente; 
critérios de indicação e contra-indicação, limitações, riscos, confiabilidade e sua validação científica;

- atuar dentro do sistema hierarquizado de saúde obedecendo aos princípios técnicos e éticos da referência e contra-referência;

- saber atuar em equipe multiprofissional, assumindo quando necessário o papel de responsável técnico, relacionando-se com os demais membros em bases éticas;

- exercer a medicina com postura ética e humanística em relação ao paciente, família e à comunidade, observando os aspectos sociais, culturais, psicológicos e econômicos relevantes do contexto, baseados nos princípios da bioética;

- ter uma visão social do papel do médico e disposição para engajase em atividades de política e de planejamento em saúde;

- informar e educar seus pacientes, familiares e comunidade em relação à promoção da saúde, prevenção, tratamento e reabilitação das doenças, usando técnicas adequadas de comunicação; - conhecer as principais características do mercado de trabalho onde deverá se inserir, procurando atuar dentro dos padrões locais, buscando o seu aperfeiçoamento considerando a política de saúde vigente;

- utilizar ou administrar recursos financeiros e materiais, observando a efetividade, visando a eqüidade e a melhoria do sistema de saúde, pautada em conhecimentos validados cientificamente.

Pelo que se acompanha do debate que vem ocorrendo nos vários fóruns nacionais e internacionais do ensino médico, não há divergências de fundo em relação ao perfil profissional necessário para os anos iniciais do próximo século. O problema central reside nas estratégias de mudança dos atuais modelos acadêmicos. Para isso é fundamental compreender adequadamente os limites $e$ as possibilidades das inovações e das reformas da educação médica frente ao perfil das práticas médicas hegemônicas e frente às estruturas sociais no contexto dos processos de globalização. Também implica compreender as contradições entre tecnologização, custo da atenção médica e eficácia; entre disciplinas e interdisciplinaridade; entre prática uniprofissional e multiprofissional; entre ética profissional e bioética e assim por diante.

A transformação das políticas públicas de educação médica e de saúde depende do correto entendimento das contradições e da vontade política das escolas e dos educadores médicos em superar o estágio da insatisfação $e$ enfrentar os desafios de construção do novo modelo de formação. 
Ademais, é decisivo reconhecer que os agudos problemas atuais do processo de formação de médicos são paradigmáticos no campo da saúde, da educação, e fazem parte também de uma crise mais ampla da universidade. Como apontou Belaciano $\left(1998\right.$, p.2) durante o recente $36^{\circ}$ Congresso Brasileiro de Educação Médica e $8^{\circ}$ Fórum Nacional de Avaliação do Ensino Médico,

\begin{abstract}
A sobrevivência da universidade depende de sua reinserção na sociedade, da construção de novas relações e de um novo papel socialmente mais relevante e a mudança da formação do médico tem que se dar ancorada nessas novas necessidades (...) devemos fazer uma articulação estratégica das Escolas com os sistemas locais de saúde. A mudança da Escola Médica não pode ser gerada, construída apenas com os atores internos à Universidade e tampouco a mudança da saúde prescinde da ação articulada com a Universidade (qualificação de recursos humanos, humanização da atenção, custos etc). A parceria é estratégica para os dois e pode ser fundamental para gerar força política e até os recursos necessários para a implementação do processo de mudança.
\end{abstract}

\title{
Referências bibliográficas
}

ALMEIDA, M.J. Educação médica e saúde: limites e possibilidades das propostas de mudança. São Paulo, 1997, 316p. Tese (Doutorado) Faculdade de Saúde Pública, Universidade de São Paulo.

ANDRADE, J. Marco conceptual de la educación médica en la America

Latina. Washington: OPS, 1979. (Desarrollo de Recursos Humanos, 28).

AROUCA, A.S.S. O dilema preventista: contribuição para a compreensão $e$ crítica da medicina preventiva. Campinas, 1975. 261p. Tese (Doutorado)

- Faculdade de Ciências Médicas, Universidade Estadual de Campinas.

BELACIANO, M.I. Considerações gerais a respeito do Projeto CINAEM - III FASE . Recife, 1998. (versão agosto de 1998). (Mimeogr.)

DONNANGELO, M. C. Medicina e sociedade: o médico e seu mercado de trabalho. São Paulo: Pioneira, 1975.

FEUERWERKER, L.C.M. Mudanças na educação médica e residência médica no Brasil. São Paulo, 1997. 229p. Dissertação (Mestrado) - Faculdade de Saúde Pública, Universidade de São Paulo.

GARCIA, J.C. La educación médica en la America Latina. Washington: OPS, 1972.

NUNES, E.D., Juan César García: pensamento social em saúde na América Latina. São Paulo: Cortez, 1989.

REDE UNIDA. Contribuição para as novas diretrizes curriculares dos cursos de graduação da área de saúde. Olho Mágico, v.4, p. 11-35, 1998.

SCHRAIBER, L. B. Educação médica e capitalismo: um estudo das relações educação e prática médica na ordem social capitalista. São Paulo: Hucitec, 1989.

132 Interface - Comunic, Saúde, Educ 4 